\title{
Impact of inflammation on the biomarkers of iron status in a cross-sectional survey of Lao women and children
}

\author{
Jacqueline Knowles $^{1 *}$, David I. Thurnham ${ }^{2}$, Bounthom Phengdy ${ }^{3}$, Keonakhone Houamboun ${ }^{4} \dagger$, \\ Khamseng Philavong ${ }^{5}$, Intong Keomoungkhone ${ }^{6}$ and Khamhoung Keovilay ${ }^{6} \neq$ \\ ${ }^{1}$ Public Nutrition Solutions Limited, Bangkok, Thailand \\ ${ }^{2}$ University of Ulster, Coleraine, $U K$ \\ ${ }^{3}$ Hygiene and Prevention Department, Ministry of Health, Vientiane, Lao People's Democratic Republic \\ ${ }^{4}$ Institute of Public Health, Ministry of Health, Vientiane, Lao People's Democratic Republic \\ ${ }^{5}$ Maternal and Child Health Centre, Ministry of Health, Vientiane, Lao People's Democratic Republic \\ ${ }^{6}$ UNICEF, Vientiane, Lao People's Democratic Republic \\ (Submitted 22 June 2012 - Final revision received 3 April 2013 - Accepted 11 April 2013 - First published online 19 June 2013)
}

\begin{abstract}
Anaemia is prevalent in South East Asia and Fe deficiency (ID) is considered to be the main cause, but the role of subclinical inflammation in the aetiology is uncertain. In the present study, we determined the influence of inflammation on the biomarkers of Fe status in women and children, and herein, we discuss the proportion of anaemia associated with ID. As part of the 2006 Lao People's Democratic Republic (The Lao PDR) National Nutrition Survey, blood collected from 482 young children and 816 non-pregnant women was analysed. Plasma ferritin, transferrin receptor (sTfR), Hb, C-reactive protein (CRP) and $\alpha$-1-acid glycoprotein (AGP) concentrations were measured. ID was assessed using ferritin concentrations ( $<12$ (children) or $<15$ (adults) $\mu \mathrm{g} / \mathrm{l}$ ), sTfR concentrations $(>8 \cdot 3 \mathrm{mg} / \mathrm{l})$ and body Fe stores (BIS $<0$ ). Elevated CRP $(>5 \mathrm{mg} / \mathrm{l})$ and/or AGP $(>1 \mathrm{~g} / \mathrm{l})$ concentrations were used to categorise inflammation status in order to correct the Fe biomarkers for inflammation. Inflammation was present in $14 \%$ of adults and $43 \%$ of children. Anaemia was present in $37.6 \%$ of both women ( Hb concentrations $<120 \mathrm{~g} / \mathrm{l}$ ) and children (Hb concentrations $<110 \mathrm{~g} / \mathrm{l}$ ). Correcting ferritin concentrations for inflammation increased the prevalence of ID from 24.3 to $26 \%$ for women and from 18 to $21 \%$ for children $(P<0 \cdot 001$ for both). Ferritin concentrations were more helpful in detecting ID than sTfR concentrations or BIS, but regression analysis found that sTfr concentrations explained more of the variance in $\mathrm{Hb}$ concentrations in both women (20\%) and children (17\%) than ferritin concentrations ( 5 and $1.4 \%$, respectively). Nevertheless, the total variance in $\mathrm{Hb}$ concentrations explained was only 26 and $18 \%$ in women and children, respectively, and other factors may be more important than ID in contributing to anaemia in The Lao PDR.
\end{abstract}

Key words: Ferritin: Soluble transferrin receptors: C-reactive protein: $\alpha$-1-Acid glycoprotein: Body iron stores: Anaemia

Despite a wealth of initiatives to improve Fe status, Fe deficiency remains one of the most widespread nutritional deficiencies in the world. A contributing issue affecting the ability to effectively plan, implement and monitor effective interventions is the absence of an internationally agreedupon epidemiological methodology to assess Fe status. Serum ferritin concentrations are believed to be the best marker for measuring Fe deficiency in a population as they are a measure of storage Fe. The blood concentration of ferritin is, however, increased by inflammation, and a report by the WHO has suggested that ferritin measurements in apparently healthy persons should be accompanied by the measurement of one or more acute-phase proteins (APP) to detect for the presence of inflammation. Different approaches have been proposed to handle data where inflammation is detected, including discarding the results ${ }^{(1)}$, using a higher ferritin cutoff to determine deficiency ${ }^{(2)}$ and using a method to adjust ferritin concentrations for the influence of inflammation ${ }^{(3)}$. The prevalence of inflammation in communities can be considerable as reported in a recent Gambian study where more than $90 \%$ of apparently healthy infants had raised APP levels at some time during the study ${ }^{(4)}$; therefore, discarding

Abbreviations: AGP, $\alpha$-1-acid glycoprotein; APP, acute-phase proteins; BIS, body iron stores; CF, correction factors; CRP, C-reactive protein; The Lao PDR, The Lao People's Democratic Republic; sTfR, soluble transferrin receptors.

*Corresponding author: J. Knowles, email jacky@publicnutritionsolutions.com

†Deceased.

$\ddagger$ Present address: Lao Statistics Bureau, Ministry of Planning and Investment, Lao People’s Democratic Republic. 
data may not be an option. In addition, using a higher ferritin cut-off to determine deficiency is imprecise since the correction affects individuals both with and without Fe deficiency. To overcome these problems, it has been shown that ferritin concentrations can be adjusted to remove the effect of inflammation using two APP: C-reactive protein (CRP) and $\alpha$-1-acid glycoprotein (AGP) ${ }^{(5)}$.

The concentration of soluble transferrin receptors (sTfR) in plasma has also been suggested as a measure of Fe deficiency. Transferrin receptors are increased on cell membranes when $\mathrm{Fe}$ is lacking in the cytosol and the amount of sTfR in plasma is proportional to the amount on cell membranes ${ }^{(6)}$. There is a much smaller effect of inflammation on $\operatorname{sTfR}^{(7)}$, but currently there is no universally accepted standard for this assay. In addition, various ratios of sTfR:ferritin concentrations have been proposed to improve the ability of the assays to predict $\mathrm{Fe}$ stores or $\mathrm{Fe}$ status $^{(8)}$. It is not known whether the ratios overcome the limitations caused by inflammation. One such ratio is the measure of body $\mathrm{Fe}$ stores (BIS) proposed by Cook et al. ${ }^{(8)}$, and this is examined in the present study.

Inflammation is caused by infection or physical damage and is well known to alter Fe metabolism and Fe mobilisation ${ }^{(9)}$. Even after the clinical effects of a disease or trauma have subsided, inflammation continues. Thus, in any apparently healthy population, there will be some subjects with subclinical evidence of inflammation ${ }^{(10,11)}$. CRP and AGP are positive APP produced at different times and in different amounts in response to inflammation. Using these proteins, we can detect the incubation phase (before clinical evidence of the disease occurs) and early and late convalescence ${ }^{(10)}$ (when symptoms are no longer present) and quantify the differences in ferritin concentrations between the apparently healthy subjects with and without inflammation. Using this method, correction factors (CF) have previously been produced to remove the influence of inflammation from the assessment measurements of retinol ${ }^{(10)}$, ferritin ${ }^{(5)}$ and some other nutrients $^{(3)}$. To date, no meta-analysis has been done to provide CF for sTfR or the ratios of sTfR:ferritin concentrations to calculate BIS. In the present study, we examine the influence of inflammation on the biomarkers of Fe status, including ferritin, STfR and BIS, in non-pregnant women of reproductive age and children aged 6-59 months, and discuss the associations of anaemia with each biomarker.

\section{Methods}

\section{Subjects}

Subjects were recruited from a subsample of households included in the 2006 Lao Multiple Indicator Cluster Survey (MICS3). The MICS3 was designed to provide estimates for a large number of maternal and child situational indicators. A systematic sample of twenty households was drawn from a listing of households in 300 enumeration areas (making 6000 households in total) ${ }^{(12)}$. Sampling was based on probability proportional to size, stratified by region (north, central and south). For the nutrition component of the survey, blood samples were requested from all eligible individuals in every second household of every fourth MICS3 enumeration area (i.e. ten households from seventy-five enumeration areas, totalling 750 households).

The household response rate for the nutrition component was 98.4\%. Of the 986 non-pregnant women (aged 15-49 years) and 580 children (aged 6-59 months) identified as living in the selected households, 927 women were successfully interviewed and questionnaires were completed for 577 children.

Plasma ferritin, sTfR, CRP and AGP concentrations were measured in 482 of 514 children aged 6-59 months (overall response rate $81.8 \%$ ) and in 816 of 927 non-pregnant women aged 15-49 years (overall response rate $81.4 \%$ ). The remaining thirty-two children and 111 women had undergone incomplete plasma tests or failed to provide other information. $\mathrm{Hb}$ measurements were available for 812 women and 479 children (overall response rates 81.0 and $81.3 \%$, respectively). Sample weights were calculated and used in the nutrition survey report; however, weighting was not considered essential for the investigation reported in the present study, so unweighted data are used here.

\section{Sample collection}

Capillary blood samples were collected from eligible women and children in the field by performing a fingerstick procedure (or by heel stick for children aged 6-11.9 months). All subjects were apparently healthy; that is, they were performing their normal functions and did not require any medical intervention. After discarding the first drop, 350-500 $\mu$ l of blood were collected into a $500 \mu \mathrm{l}$ EDTA Microtainer ${ }^{\circledR}$ and a HemoCue $^{\circledR}$ cuvette was filled with whole blood from the Microtainer for the analysis of $\mathrm{Hb}$. The remaining blood was centrifuged, within half an hour of collection, using a Sarstedt MC-6 motorcycle battery-powered portable micro-centrifuge (Model MC-6; Sarstedt). Plasma was pipetted into barcodelabelled cryovials and put into a cool box with icepacks until it could be transferred to a freezer; the time delay before freezing varied from a few minutes to $24 \mathrm{~h}$. Blind measurements of field quality-control material exposed to both extremes did not differ significantly (data not shown).

\section{Analysis of ferritin, soluble transferrin receptor, C-reactive protein, $\alpha$-1-acid glycoprotein and $\mathrm{Hb}$ concentrations}

Plasma ferritin, sTfR, CRP and AGP concentrations were measured at the DBS-Tech laboratory in Germany using ELISA methods ${ }^{(13)}$ that require only $30 \mu$ l plasma to produce measurements for all the four indicators. Blind quality-control samples provided by the US Centers for Disease Control and Prevention (CDC) Micronutrient Laboratory were included with the samples for analysis, together with those that had been transported to the field and kept under field conditions along with the survey samples. Staff from the US CDC laboratory conducted a review of the quality of all data once analysis was finalised and were satisfied with the methodology. 
$\mathrm{Hb}$ concentrations were measured using the HemoCue ${ }^{\circledR}$ B-Hemoglobin System, according to the manufacturer's instructions. The machines were calibrated daily and checked at the start and end of the day using high-, mid- and low-quality controls.

\section{Data handling}

Correction of plasma ferritin and sTfR concentrations for current inflammation was done as follows. The subjects were categorised into four groups: a reference group and three inflammation groups. In the 'reference group', the subjects had normal AGP $(\leq 1.0 \mathrm{~g} / \mathrm{l})$ and normal CRP $(\leq 5 \mathrm{mg} / \mathrm{l})$ concentrations. The inflammation groups were described as 'incubation' (normal AGP concentrations $<1 \mathrm{~g} / 1$ and elevated CRP concentrations $>5 \mathrm{mg} / \mathrm{l}$ ), 'early convalescence' (CRP and AGP concentrations were both elevated) and 'late convalescence' (only AGP concentration was elevated).

The effect of inflammation on the Fe biomarkers was removed using CF for each of the inflammation groups. The CF used for ferritin were those determined in a meta-analysis: $0.77,0.53$ and $0.75^{(14)}$, and these values were multiplied by all data in the incubation, early convalescence and late convalescence groups, respectively. In addition, we calculated specific CF for ferritin and STfR based on the data obtained in the present study as the ratios of the geometric means of the 'reference' group to those of the respective inflammatory groups, and these were determined for the women and children separately. CF for sTfR were used to correct sTfR concentrations as described for ferritin. CF for $\mathrm{Hb}$ were calculated using the ratios of the arithmetic means and used as described for ferritin. Cut-offs to define Fe deficiency were for plasma ferritin concentrations $<12 \mu \mathrm{g} / \mathrm{l}$ for children and $<15 \mu \mathrm{g} /$ l for women $^{(15)}$, for plasma sTfR concentrations $>8.3 \mathrm{mg}$ / $\mathrm{l}^{(13)}$, and for BIS $<0.01 \mathrm{mg} / \mathrm{kg}$. The cut-off to define anaemia was $\mathrm{Hb}<120 \mathrm{~g} / \mathrm{l}$ for women and $<110 \mathrm{~g} / \mathrm{l}$ for children ${ }^{(2)}$.

BIS were calculated using the raw data, but for the inflammation-corrected BIS, only inflammation-adjusted ferritin concentrations were used in the following formula, where sTfR concentrations are given in $\mathrm{mg} / \mathrm{l}$ and ferritin concentrations are given in $\mu \mathrm{g} / \mathrm{l}^{(8)}$ :

$$
\begin{aligned}
\operatorname{Body~Fe}(\mathrm{mg} / \mathrm{kg})= & -\left(\log _{10}(\mathrm{sTfR} \times 1000 / \text { ferritin })\right. \\
& -2 \cdot 8229) / 0 \cdot 1207 .
\end{aligned}
$$

$\mathrm{Hb}$ values were adjusted for altitude ${ }^{(16)}$. In total, $3 \cdot 8 \%$ of women and $4 \%$ of children lived at altitudes between 1000 and $1250 \mathrm{~m}$ (adjustment $-2 \mathrm{~g} / \mathrm{l}$ ), while $1.6 \%$ of women and $2 \cdot 2 \%$ of children lived at altitudes above $1250 \mathrm{~m}$ (adjustment $-5 \mathrm{~g} / \mathrm{l}$ ) (no global positioning system (GPS) data were available for $1.8 \%$ of the sample). Adjustment for altitude resulted in the categorisation of four additional women and one additional child as having anaemia.

\section{Statistical methods}

Differences in the prevalence of elevated AGP, CRP or APP concentrations between demographic and other categories were tested using the Kruskal-Wallis test. Calculations of Pearson's skewness coefficient for the women's data indicated that both ferritin and STfR concentrations were positively skewed. Plasma ferritin and sTfR concentrations were transformed to log (base 10) values for statistical analyses. However, four of the women's ferritin values were zero; therefore, these were converted to $0.05 \mu \mathrm{g} / 1$ to enable the calculation of the logarithms. The difference in ferritin, sTfR or $\mathrm{Hb}$ concentrations between the inflammation groups was determined using ANOVA (of the log 10-transformed data for ferritin and sTfR). Differences in concentrations between individual inflammation groups were calculated using the least significant difference $t$ test.

Measurements of BIS were negatively skewed and not easily normalised by transformation. Differences between the groups were tested using the Kruskal-Wallis test or the Mann-Whitney test for pairs of groups.

Bivariate Pearson's correlation coefficients were calculated for the $\log$ (base 10)-transformed, inflammation-corrected $\mathrm{Hb}$ concentrations, the Fe biomarkers (corrected BIS and $\log _{10}$ ferritin and uncorrected sTfR concentrations) and the log (base 10)-transformed APP (CRP and AGP) concentrations. To determine the factors explaining inflammation-corrected $\mathrm{Hb}$ concentrations, we used a stepwise, multiple linear regression analysis with the same variables.

The present study was conducted according to the guidelines laid down in the Declaration of Helsinki, and all procedures involving human subjects/patients were approved by the National Ethics Committee for Health Research, the Lao People's Democratic Republic (The Lao PDR). Written informed consent was obtained from all the subjects/patients.

\section{Results}

All data were collected from apparently healthy people. Among children aged 6-59 months, 43.0\% (207/482) were found to have elevated APP concentrations, indicative of subclinical inflammation (Table 1). A raised CRP concentration was observed in $16 \%$ of children of both sexes, while AGP concentration was raised in $43.8 \%$ of boys and $36.7 \%$ of girls; this difference between sexes was not significant $(P=0 \cdot 14)$. Among the non-pregnant women aged 15-49 years, $14.5 \%$ (118/816) were found to have elevated APP concentrations. Table 1 also shows factors significantly associated with subclinical inflammation; for both groups, we examined associations with domicile (region within The Lao PDR and urban or rural location), age, mothers' education and wealth quintiles (created from the MICS-generated wealth index $)^{(17,18)}$.

There was significantly less subclinical inflammation in children living in the northern region than in those living in the central and southern regions of The Lao PDR; younger children had more inflammation than older children, and children of mothers with a secondary education showed slightly more inflammation than those with mothers with none or only primary education. For women, there was significantly less inflammation in those living in the more inaccessible rural areas, and there were differences between different age 
Table 1. Distribution of children and women with raised acute-phase protein concentrations by background characteristics

(Number of subjects and percentages; medians and interquartile ranges (IQR))

\begin{tabular}{|c|c|c|c|c|c|c|c|c|c|c|c|c|c|}
\hline \multirow[b]{2}{*}{ Group/category } & \multirow[b]{2}{*}{ Subgroup } & \multirow[b]{2}{*}{$n$} & \multirow[b]{2}{*}{$\%$} & \multicolumn{3}{|c|}{ Plasma CRP (mg/l) } & \multirow[b]{2}{*}{$P^{*}$} & \multicolumn{3}{|c|}{ Plasma AGP (g/l) } & \multirow[b]{2}{*}{$P^{*}$} & \multirow[b]{2}{*}{$\begin{array}{l}\text { Raised CRP } \\
\text { or AGP (\%) }\end{array}$} & \multirow[b]{2}{*}{$P \dagger$} \\
\hline & & & & Median & IQR & $\begin{array}{c}\% \\
(>5 \mathrm{mg} / \mathrm{l})\end{array}$ & & Median & IQR & $\begin{array}{c}\% \\
(>1 \mathrm{~g} / \mathrm{l})\end{array}$ & & & \\
\hline \multirow[t]{2}{*}{ Children's sex } & Male & 242 & $50 \cdot 2$ & 0.72 & $0.19-2.98$ & $15 \cdot 7$ & \multirow[t]{2}{*}{0.138} & 0.94 & $0.76-1.18$ & $43 \cdot 8$ & \multirow[t]{2}{*}{0.136} & $47 \cdot 1$ & \multirow[t]{2}{*}{0.064} \\
\hline & Female & 240 & 49.8 & 0.54 & $0.11-2 \cdot 38$ & $15 \cdot 8$ & & 0.89 & $0 \cdot 71-1 \cdot 17$ & $36 \cdot 7$ & & $38 \cdot 8$ & \\
\hline \multirow[t]{3}{*}{ Children's region } & North & 157 & $32 \cdot 6$ & 0.49 & $0.13-2.07$ & $10 \cdot 8$ & \multirow[t]{3}{*}{0.254} & 0.84 & $0.67-1.06$ & 29.9 & \multirow[t]{3}{*}{0.004} & $31 \cdot 8$ & \multirow[t]{3}{*}{0.002} \\
\hline & Central & 165 & 34.2 & 0.72 & $0.16-4.01$ & $18 \cdot 2$ & & 0.93 & $0.76-1.21$ & $44 \cdot 8$ & & $46 \cdot 7$ & \\
\hline & South & 160 & $33 \cdot 2$ & 0.74 & $0.16-2.72$ & $18 \cdot 1$ & & 0.95 & $0.75-1.23$ & $45 \cdot 6$ & & $50 \cdot 0$ & \\
\hline \multirow[t]{5}{*}{ Children's age (months) } & $6-11$ & 35 & $7 \cdot 3$ & 1.89 & $0.45-4.78$ & $22 \cdot 9$ & \multirow[t]{5}{*}{0.001} & 1.04 & $0.75-1.32$ & $54 \cdot 3$ & \multirow[t]{5}{*}{0.114} & $60 \cdot 0$ & \multirow[t]{5}{*}{0.079} \\
\hline & $12-23$ & 100 & $20 \cdot 7$ & 1.07 & $0.32-4.30$ & $19 \cdot 0$ & & 0.98 & $0.75-1.22$ & $45 \cdot 0$ & & $49 \cdot 0$ & \\
\hline & $24-35$ & 128 & $26 \cdot 6$ & 0.58 & $0.09-2.80$ & $18 \cdot 0$ & & 0.90 & $0.71-1.27$ & $42 \cdot 2$ & & 43.0 & \\
\hline & $36-47$ & 112 & $23 \cdot 2$ & 0.47 & $0.12-1.98$ & $12 \cdot 5$ & & 0.90 & $0.74-1.11$ & 33.9 & & 37.5 & \\
\hline & $48-59$ & 107 & $22 \cdot 2$ & 0.40 & $0.09-1.45$ & $11 \cdot 2$ & & 0.86 & $0.65-1 \cdot 12$ & $35 \cdot 5$ & & 37.4 & \\
\hline \multirow[t]{3}{*}{ Children by mother's education $\ddagger$} & None & 179 & $37 \cdot 1$ & 0.72 & $0.19-2.96$ & $15 \cdot 1$ & \multirow[t]{3}{*}{0.003} & 0.91 & $0.71-1.15$ & 38.0 & \multirow[t]{4}{*}{0.223} & $41 \cdot 3$ & \multirow[t]{4}{*}{0.187} \\
\hline & Primary & 222 & $46 \cdot 1$ & 0.43 & $0.07-2.39$ & $15 \cdot 3$ & & 0.91 & $0.72-1.17$ & $40 \cdot 1$ & & $42 \cdot 3$ & \\
\hline & Secondary§ & 71 & 14.7 & 1.25 & $0.39-4.14$ & $19 \cdot 7$ & & 1.01 & $0.78-1.21$ & $50 \cdot 7$ & & 53.5 & \\
\hline Total children & & \multicolumn{2}{|c|}{482} & & & $15 \cdot 8$ & & & & $40 \cdot 2$ & & $42 \cdot 9$ & \\
\hline \multirow[t]{3}{*}{ Women's area } & Urban & 192 & 23.5 & 0.64 & $0.10-1.90$ & 9.9 & \multirow[t]{3}{*}{0.000} & 0.71 & $0.60-0.86$ & 7.8 & 0.811 & $14 \cdot 6$ & 0.977 \\
\hline & Rural - road & 473 & $58 \cdot 0$ & 0.37 & $0.09-1.47$ & $8 \cdot 7$ & & 0.69 & $0.59-0.85$ & $10 \cdot 1$ & & $14 \cdot 6$ & \\
\hline & Rural - no road & 151 & 18.5 & 0.23 & $0.05-0.63$ & $2 \cdot 6$ & & 0.70 & $0.59-0.86$ & $12 \cdot 6$ & & 13.9 & \\
\hline Women's age (years) & $15-19$ & 170 & $20 \cdot 8$ & 0.15 & $0.03-0.58$ & $2 \cdot 4$ & 0.000 & 0.77 & $0.64-0.87$ & $11 \cdot 8$ & 0.013 & $12 \cdot 9$ & 0.862 \\
\hline & $20-24$ & 129 & $15 \cdot 8$ & 0.30 & $0.06-1.21$ & $7 \cdot 0$ & & 0.68 & $0.56-0.85$ & 8.5 & & $13 \cdot 2$ & \\
\hline & $25-29$ & 118 & 14.5 & 0.35 & $0.08-1.44$ & 8.5 & & 0.70 & $0.59-0.85$ & $12 \cdot 7$ & & $16 \cdot 9$ & \\
\hline & $30-34$ & 121 & 14.8 & 0.50 & $0.13-1.74$ & 11.6 & & 0.65 & $0.56-0.83$ & $9 \cdot 1$ & & 14.0 & \\
\hline & $35-39$ & 118 & 14.5 & 0.77 & $0.19-2.06$ & $9 \cdot 3$ & & 0.69 & $0.57-0.88$ & $13 \cdot 6$ & & $17 \cdot 8$ & \\
\hline & $40-44$ & 100 & $12 \cdot 3$ & 0.54 & $0.23-1.94$ & $12 \cdot 0$ & & 0.72 & $0.62-0.84$ & $5 \cdot 0$ & & $14 \cdot 0$ & \\
\hline & $45-49$ & 60 & $7 \cdot 4$ & 0.28 & $0.11-1.96$ & 6.7 & & 0.66 & $0.56-0.89$ & $6 \cdot 7$ & & 11.7 & \\
\hline Total women & & & & & & $7 \cdot 8$ & & & & $10 \cdot 0$ & & 14.5 & \\
\hline
\end{tabular}

CRP, C-reactive protein; AGP, $\alpha$-1-acid glycoprotein

P value indicates significance of the difference between mean rankings for CRP or AGP values within a category $\left(P<0.05 ; \chi^{2}\right.$ Kruskal-Wallis non-parametric test).

$\dagger P$ value indicates significance of the difference between mean rankings for the prevalence of elevated CRP or AGP concentrations within a category $\left(P<0.05 ; \chi^{2}\right.$ Kruskal-Wallis non-parametric test)

$\ddagger$ Analysis excludes ten children whose mothers had completed a non-standard curriculum.

$\S$ Secondary education or higher. 
groups, but no significant trend was observed. There were tendencies for CRP concentrations to be different in women by education status $(P=0.063)$ and wealth quintiles $(P=0 \cdot 058)$, but there were no trends, and AGP concentrations did not differ between the subgroups (data not shown).

The influence of inflammation on serum ferritin concentrations is shown in Table 2. In the uncorrected data from women, ferritin concentration was significantly higher than that in the reference group for the incubation and early convalescence groups but not for the late convalescence group. Subclinical inflammation was present in $14.5 \%(118 / 816)$ of the women altogether. After correction of the data for subclinical inflammation using CF from the meta-analysis ${ }^{(14)}$, there were no significant differences in ferritin concentrations between the four groups (Table 2). Before correction, the proportion of low ferritin values indicating Fe deficiency in women with inflammation $(18 \%, 21 / 118)$ was slightly lower than those in the reference group $(25 \%, 177 / 698)$. Correcting the ferritin data for inflammation using the meta-analysis CF increased the prevalence of Fe deficiency among women with inflammation to $28 \%(33 / 118)$ and among all women from $24 \%(198 / 816)$ to $26 \%(210 / 816)$. Correcting the ferritin data for inflammation using internally generated CF gave comparable increases in the prevalence of Fe deficiency of $27 \%$ (32/118) among women with inflammation and 26\% among all women $(P<0.001$ for the overall change in Fe deficiency using both $\mathrm{CF}$ ).

Among children, ferritin concentrations were higher in all the three inflammation groups when compared with values in the reference group, although values in the incubation group did not quite reach significance $(P=0 \cdot 067)$. There were 207 (43\%) children in the groups with inflammation, which was a value higher than that found for women in these groups (15\%). Before correction, Fe deficiency (ferritin concentrations $<12 \mu \mathrm{g} / \mathrm{l}$ ) was present in a higher proportion of children in the reference group $(21 \%, 58 / 275)$ than in those in the inflammation groups $\left(14 \%, 29 / 207 ; \chi^{2}\right.$ test: $P=0.045)$. After the data were corrected for the presence of inflammation using CF from the meta-analysis or internally generated CF, there was no longer any difference in ferritin concentrations in the different groups, and the prevalence of $\mathrm{Fe}$ deficiency among children in the inflammation groups increased (22\%, 45/207 meta-analysis CF; 21\%, 43/207 internally generated CF) and was comparable with that among children in the reference group. Correcting ferritin concentrations for inflammation in children increased the total proportion of children with Fe deficiency (ferritin concentrations $<12 \mu \mathrm{g} / \mathrm{l}$ ) from $18 \%(87 / 482)$ to $21 \%$ (103/482 using meta-analysis CF or $101 / 482$ using internal survey CF $)(P<0 \cdot 001)$.

Plasma sTfR concentrations among women and children are shown in Table 3. Inflammation had a smaller effect on plasma sTfR concentrations than on ferritin concentrations, but median values in the convalescence groups were higher than those in their respective reference group. However, for the incubation group in women, the median value was significantly lower than the reference value. Fe deficiency was defined using a cut-off $>8.3 \mathrm{mg} / \mathrm{l}^{(13)}$, though using this criterion gave substantially lower estimates for the prevalence of Fe deficiency than those obtained using the ferritin cutoffs (Table 2). In order to correct the data for inflammation, we calculated CF for the respective inflammation groups and for the women and children separately (Table 3). After correction, there were no significant differences in sTfR concentrations between the reference and inflammation groups for either women or children. Correction also made very little difference to the estimates of Fe deficiency obtained using STfR concentrations; in women and children, the prevalence of Fe deficiency using sTfR concentrations fell from 6 to $5 \%$ and 4 to $3 \%$ (both $P=0 \cdot 25$ ), respectively.

We also determined BIS using the ferritin and sTfR concentrations available for women and children (Table 4). To correct BIS for inflammation, we used the inflammation-adjusted ferritin results but the uncorrected STfR results. It was realised after correcting STfR concentrations for inflammation (Table 3) that inflammation and Fe deficiency were having the same effect on sTfR, i.e. increasing values; thus, the method used to correct sTfR concentrations was potentially invalid and only removing subjects with Fe deficiency. After correction, differences between median BIS values for the reference group and the groups with inflammation still remained in women $(P=0.002)$, but were removed by correction in children. Correction caused a small increase in the number of subjects with Fe deficiency, as defined by zero BIS $(<0.01 \mathrm{mg} / \mathrm{kg})$ in both cases (women 13-14\%, $P=0.045$; children $12-14 \%, P=0.005)$. These differences in the proportions of subjects with zero BIS were the same whether we used inflammation-adjusted ferritin and sTfR concentrations or the internally generated CF to correct for inflammation (data not shown). We also calculated the proportion of women and children with BIS below 6 and $3 \mathrm{mg} / \mathrm{kg}$, respectively, as an alternative estimate of $\mathrm{Fe}$ deficiency. These cut-offs were selected to include all subjects with low ferritin concentrations (women $<15 \mu \mathrm{g} / 1$ and children $<12 \mu \mathrm{g} / \mathrm{l}$ ) within the respective low-BIS groups. Correction for inflammation significantly increased the number of women $(38-39 \%)$ and children $(27-30 \%)$ with low BIS $(P<0 \cdot 05)$.

The effects of inflammation on $\mathrm{Hb}$ concentrations are shown in Table 5. There were significant differences in mean $\mathrm{Hb}$ concentrations between the reference group and some of the inflammation groups before correction for both women and children, but these were removed by correction. After correction, there was a small non-significant increase in women with anaemia ( $\mathrm{Hb}$ concentrations $<120 \mathrm{~g} / \mathrm{l}$; $37 \cdot 3-37 \cdot 6 \%)$ and a significant reduction in children (Hb concentrations $<110 \mathrm{~g} / 1 ; 40 \cdot 5-37 \cdot 6 \%, P<0 \cdot 001)$.

After correcting $\mathrm{Hb}$ concentrations for inflammation, anaemia was present in $37.6 \%(305 / 812)$ of women (Table 5); Fe-deficiency anaemia ( $\mathrm{Hb}$ concentrations $<120 \mathrm{~g} / \mathrm{l}$ and ferritin concentrations $<15 \mu \mathrm{g} / \mathrm{l})$ was present in $16 \%(132 / 812)$ and Fe deficiency was present in $26 \%$ (Table 2). In children, anaemia was present in $37 \cdot 6 \%(180 / 479)$ with no difference between the prevalence among the boys (40\%, 97/240) and that among the girls $(34 \cdot 7 \%, 83 / 239)\left(\chi^{2}\right.$ test: $\left.P=0 \cdot 129\right)$. There was more Fe-deficiency anaemia in the boys than in the girls ( $\chi^{2}$ test: 17 and 9\%,P=0.027), but Fe deficiency alone was not significantly different (24 and $18.8 \%$ in the 
Table 2. Influence of inflammation on plasma ferritin concentrations in non-pregnant women and children ${ }^{\star} \dagger$ (Number of subjects and percentages; medians and interquartile ranges (IQR))

\begin{tabular}{|c|c|c|c|c|c|c|c|c|c|c|c|c|c|c|c|c|c|c|c|c|c|c|}
\hline & \multirow[b]{2}{*}{ Variables } & \multicolumn{4}{|c|}{ Reference } & \multicolumn{4}{|c|}{ Incubation } & \multicolumn{4}{|c|}{ Early convalescence } & \multicolumn{4}{|c|}{ Late convalescence } & \multirow[b]{2}{*}{$P \S$} & \multicolumn{4}{|c|}{ Total } \\
\hline & & $n$ & $\%$ & Median & IQR & $n$ & $\%$ & Median & IQR & $n$ & $\%$ & Median & IQR & $n$ & $\%$ & Median & IQR & & $n$ & $\%$ & Median & IQR \\
\hline Women & $\begin{array}{l}\text { Number of } \\
\text { women }(n)\end{array}$ & & & 698 & & & & 36 & & & & 28 & & & & 54 & & & & & 816 & \\
\hline Uncorrected & $\begin{array}{l}\text { Ferritin }(\mu \mathrm{g} / \mathrm{l}) \\
\text { ID }\end{array}$ & 177 & 25 & $39.0^{\mathrm{a}}$ & $14 \cdot 8-73 \cdot 9$ & 4 & 11 & $56 \cdot 2^{\mathrm{b}}$ & $26 \cdot 6-190 \cdot 8$ & 2 & 7 & $61 \cdot 0^{\mathrm{b}}$ & $25 \cdot 3-139 \cdot 2$ & 15 & 28 & $39 \cdot 7^{\mathrm{a}}$ & $13 \cdot 3-76 \cdot 2$ & 0.001 & $198^{w}$ & $24 \cdot 3$ & $40 \cdot 1$ & $15 \cdot 6-78 \cdot 7$ \\
\hline Corrected (MA) & $\begin{array}{l}\text { Ferritin (MA) } \\
(\mu \mathrm{g} /) \\
\operatorname{ID}(\mathrm{MA})\end{array}$ & 177 & 25 & $39 \cdot 0^{\mathrm{a}}$ & $14 \cdot 8-73.9$ & 6 & 17 & $43 \cdot 3^{\mathrm{a}, \mathrm{b}}$ & $20 \cdot 5-146 \cdot 9$ & 7 & 25 & $32 \cdot 3^{\mathrm{a}}$ & $13 \cdot 4-73 \cdot 8$ & 20 & 37 & $29 \cdot 8^{\mathrm{a}, \mathrm{c}}$ & $10 \cdot 0-57 \cdot 2$ & 0.17 & $210^{x}$ & 26 & 38.6 & $14 \cdot 7-74 \cdot 0$ \\
\hline $\begin{array}{r}\text { Corrected (Lao } \\
\text { survey data) }\end{array}$ & $\begin{array}{l}\text { Ferritin (Lao) } \\
(\mu \mathrm{g} / \mathrm{l})\end{array}$ & & & 39.7 & $39 \cdot 0-14 \cdot 8$ & & & $30 \cdot 6$ & $14 \cdot 5-104.0$ & & & 30.0 & $12 \cdot 4-68 \cdot 5$ & & & 38.6 & $12 \cdot 9-74 \cdot 1$ & 1.00 & & & 38.7 & $14 \cdot 7-73 \cdot 9$ \\
\hline Children & $\begin{array}{l}\text { ID (Lao) } \\
\text { Number of } \\
\text { children }(n)\end{array}$ & 177 & 25 & 275 & & 10 & 28 & 13 & & 7 & 25 & 63 & & 15 & 28 & 131 & & & $209^{x}$ & 26 & 482 & \\
\hline Uncorrected & $\begin{array}{l}\text { Ferritin }(\mu \mathrm{g} / \mathrm{l}) \\
\text { ID }\end{array}$ & 58 & 21 & $31 \cdot 1^{\mathrm{a}}$ & $13 \cdot 3-52 \cdot 6$ & 2 & 15 & $44 \cdot 7^{a, b}$ & $27 \cdot 5-67 \cdot 6$ & 6 & 10 & $47 \cdot 6^{\mathrm{b}}$ & $22 \cdot 1-100 \cdot 4$ & 21 & 16 & $36.7^{b}$ & $17 \cdot 4-71 \cdot 7$ & 0.003 & $87^{y}$ & 18 & 33.8 & $15 \cdot 6-61 \cdot 2$ \\
\hline Corrected (MA) & $\begin{array}{l}\text { Ferritin (MA) } \\
(\mu \mathrm{g} /) \\
\operatorname{ID}(\mathrm{MA})\end{array}$ & 58 & 21 & 31.1 & $13 \cdot 3-52 \cdot 6$ & 2 & 15 & 34.4 & $21 \cdot 2-52 \cdot 1$ & 16 & 25 & $25 \cdot 2$ & $11 \cdot 71-53 \cdot 21$ & 27 & 21 & 27.53 & $13 \cdot 1-53 \cdot 8$ & 0.60 & $103^{2}$ & 21 & $29 \cdot 5$ & $13 \cdot 1-52 \cdot 7$ \\
\hline $\begin{array}{r}\text { Corrected (Lao } \\
\text { survey data) }\end{array}$ & $\begin{array}{l}\text { Ferritin (Lao) } \\
(\mu \mathrm{g} / \mathrm{l}) \\
\operatorname{ID}(\mathrm{Lao})\end{array}$ & 58 & 21 & $31 \cdot 1$ & $13 \cdot 3-52 \cdot 6$ & 2 & 15 & $25 \cdot 0$ & $15 \cdot 4-37 \cdot 8$ & 14 & 22 & 28.9 & $13.4-61.04$ & 27 & 21 & $28 \cdot 3$ & $13 \cdot 4-55 \cdot 3$ & 1.00 & $101^{z}$ & 21 & $30 \cdot 2$ & $13.4-53.3$ \\
\hline
\end{tabular}

ID, Fe deficiency; MA, meta-analysis.

ID, Fe deficiency; MA, meta-analysis.
a,b,c Median values with unlike superscript letters were significantly different between the inflammation groups $(P<0.05$; least significant difference $t$ test $)$.

w, $x$ Values with unlike superscript letters were significantly different in the number of women with ID before and after correction $(P<0.05$; paired $t$ test on coded variables). There was no difference in ID between the two methods of

correction.
$y, z$ Values with unlike superscript letters were significantly different in the number of children with ID before and after correction ( $P<0.05$; paired $t$ test on coded variables). There was no difference in ID between the two methods of correction.

* Ferritin data are presented as medians and IQR. ID (ferritin concentrations $<15$ (adults) or $<12$ (children) $\mu \mathrm{g} /$ ) is shown as numbers and percentages.

†The four inflammation groups were as follows: reference, no raised acute-phase protein concentrations; incubation, only C-reactive protein (CRP) concentrations raised (>5 mg/l); early convalescence, both CRP and $\alpha-1$-acid glycoprotein (AGP) (>1 g/l) concentrations raised; late convalescence, only AGP concentrations raised.

$\ddagger$ Corrected ferritin concentrations (MA) were calculated by multiplying all data in the incubation, early convalescence and late convalescence groups by correction factors calculated from the MA: $0.77,0.53$ and 0.75 , respectively. Corrected ferritin concentrations (Lao) were calculated by multiplying all data in the incubation, early convalescence and late convalescence groups by correction factors (CF) determined using the Lao survey data only; for women, these CF were $0.55,0.49$ and 0.97 , and for children, they were $0.56,0.61$ and 0.77 , respectively.

$\S$ Differences between the inflammation groups were determined by ANOVA on logarithm (base 10)-transformed data. 
Table 3. Influence of inflammation on plasma transferrin receptor protein (sTfR) concentrations in non-pregnant women and children* ${ }^{*} \ddagger$

(Number of subjects and percentages; medians and interquartile ranges (IQR))

\begin{tabular}{|c|c|c|c|c|c|c|c|c|c|c|c|c|c|c|c|c|c|c|c|c|c|}
\hline & \multirow[b]{2}{*}{ Variables } & \multicolumn{4}{|c|}{ Reference } & \multicolumn{3}{|c|}{ Incubation } & \multicolumn{4}{|c|}{ Early convalescence } & \multicolumn{4}{|c|}{ Late convalescence } & \multirow[b]{2}{*}{$P \S$} & \multicolumn{4}{|c|}{ Total } \\
\hline & & $n$ & $\%$ & Median & IQR & $n \quad \%$ & Median & IQR & $n$ & $\%$ & Median & IQR & $n$ & $\%$ & Median & IQR & & $n$ & $\%$ & Median & IQR \\
\hline Women & $\begin{array}{l}\text { Number of } \\
\quad \text { women }(n)\end{array}$ & & & 698 & & & 36 & & & & 28 & & & & 54 & & & & & 816 & \\
\hline Uncorrected & $\begin{array}{l}\mathrm{sTfR}(\mathrm{mg} / \mathrm{l}) \\
\text { ID sTfR }>8.3 \mathrm{mg} / \mathrm{l}\end{array}$ & 37 & 5 & $3.41^{\mathrm{a}}$ & $2.71-4.55$ & 0 & $3.00^{\mathrm{b}}$ & $2.48-3.81$ & 2 & 7 & $4.77^{\circ}$ & $3.90-6.48$ & 8 & 14 & $4 \cdot 36^{\mathrm{c}}$ & $3.00-6.74$ & 0.000 & $47^{\mathrm{w}}$ & 6 & 3.48 & $2.74-4.69$ \\
\hline $\begin{array}{l}\text { Correction } \\
\text { factors }\end{array}$ & & & & & & & 1.253 & & & & 0.7565 & & & & 0.759 & & & & & & \\
\hline Corrected & $\begin{array}{l}\text { Corrected sTfR }(\mathrm{mg} / \mathrm{l}) \\
\text { ID sTfR }>8.3 \mathrm{mg} / \mathrm{l}\end{array}$ & 36 & 5 & 3.44 & $2.71-4.55$ & 0 & 3.75 & $3.11-4.77$ & 2 & 7 & 3.60 & $2 \cdot 95-4.71$ & 3 & 14 & 3.30 & $2 \cdot 31-5 \cdot 12$ & 1.00 & $41^{x}$ & 5 & 3.45 & $2.73-4.61$ \\
\hline Children & $\begin{array}{l}\text { Number of } \\
\text { children }(n)\end{array}$ & & & 275 & & & 13 & & & & 63 & & & & 131 & & & & & 482 & \\
\hline Uncorrected & $\begin{array}{l}\text { sTfR }(\mathrm{mg} / \mathrm{l}) \\
\text { ID sTfR }>8.3 \mathrm{mg} / \mathrm{l}\end{array}$ & 12 & 4 & $4.05^{\mathrm{a}}$ & $3.25-5.01$ & 0 & $4 \cdot 30^{a, c}$ & $3 \cdot 18-5 \cdot 85$ & 5 & 8 & $4.66^{\mathrm{b}, \mathrm{c}}$ & $3.59-5.71$ & 6 & 5 & $4 \cdot 31^{\mathrm{b}, \mathrm{c}}$ & $3.49-5.85$ & 0.026 & $23^{y}$ & 5 & $4 \cdot 21$ & $3 \cdot 36-5 \cdot 28$ \\
\hline $\begin{array}{c}\text { Correction } \\
\text { factors }\end{array}$ & & & & & & & 0.991 & & & & 0.873 & & & & 0.916 & & & & & & \\
\hline Corrected & $\begin{array}{l}\text { Corrected sTfR }(\mathrm{mg} / \mathrm{l}) \\
\text { ID sTfR }>8.3 \mathrm{mg} / \mathrm{l}\end{array}$ & 12 & 4 & 4.05 & $3.25-5.01$ & 0 & 4.26 & $3.15-5.80$ & 2 & 3 & 4.07 & $3.13-4 \cdot 98$ & 4 & 3 & 3.95 & $3 \cdot 20-5 \cdot 36$ & 0.993 & $18^{2}$ & 4 & 4.04 & $3.20-5.02$ \\
\hline
\end{tabular}

ID, Fe deficiency.

${ }_{\mathrm{a}, \mathrm{b}, \mathrm{c}}$ Median values with unlike superscript letters were significantly different between the inflammation groups $(P<0.05$; least significant difference $t$ test).

w,x Values with unlike superscript letters were significantly different in the number of women with ID before and after correction ( $P<0.05$; paired $t$ test on coded variables). The same results were obtained using sTfr concentrations

y,z Values with unlike superscript letters were significantly different in the number of children with ID before and after correction $(P<0.05$; paired $t$ test on coded variables). The same results were obtained using sTfr concentrations $>8.5 \mathrm{mg} / \mathrm{l}$ (data not shown)

*Plasma sTfR data are medians and quartiles. ID (sTfR concentrations $>8.3 \mathrm{mg} / \mathrm{l})$ is shown as numbers and percentages.

†The four inflammation groups were as follows: reference, no raised acute-phase protein concentrations; incubation, only C-reactive protein (CRP) concentrations raised (>5 mg/l); early convalescence, both CRP and $\alpha-1$-acid glycoprotein (AGP) (>1 g/l) concentrations raised; late convalescence, only AGP concentrations raised.

‡Correction factors were calculated using the geometric means from the logarithms (base 10) of the uncorrected sTfR values from the women and children separately.

$\S$ Differences between the inflammation groups were determined by ANOVA on logarithm (base 10)-transformed data. 
Table 4. Influence of inflammation on body iron stores (BIS) in non-pregnant women and children ${ }^{\star} \ddagger$

(Number of subjects and percentages; medians and interquartile ranges (IQR))

\begin{tabular}{|c|c|c|c|c|c|c|c|c|c|c|c|c|c|c|c|c|c|c|c|c|c|c|}
\hline \multirow[b]{2}{*}{ Groups } & \multirow[b]{2}{*}{ BIS } & \multicolumn{4}{|c|}{ Reference } & \multicolumn{4}{|c|}{ Incubation } & \multicolumn{4}{|c|}{ Early convalescence } & \multicolumn{4}{|c|}{ Late convalescence } & \multirow[b]{2}{*}{$P \S$} & \multicolumn{4}{|c|}{ Total } \\
\hline & & $n$ & $\%$ & Median & IQR & $n$ & $\%$ & Median & IQR & $n$ & $\%$ & Median & IQR & $n$ & $\%$ & Median & IQR & & $n$ & $\%$ & Median & IQR \\
\hline Women $(n)$ & & 698 & & & & 36 & & & & 28 & & & & 54 & & & & & 816 & & & \\
\hline Uncorrected BIS & $\mathrm{mg} / \mathrm{kg}$ & & & 7.35 & $3.26-10 \cdot 20$ & & & 9.14 & $6.35-13.76$ & & & 7.90 & $4.95-11.569$ & & & $6 \cdot 11$ & $1.88-9.79$ & 0.003 & & & 7.47 & $3.46-10.32$ \\
\hline ID & $<0.01$ & 99 & 14 & & & 1 & 3 & & & 0 & & & & 7 & 13 & & & & $107^{w}$ & 13 & & \\
\hline ID & $<6.0$ & 266 & 38 & & & 8 & 22 & & & 8 & 29 & & & 25 & 46 & & & & $307^{\mathrm{a}}$ & 38 & & \\
\hline Corrected BIS & $\mathrm{mg} / \mathrm{kg}$ & & & 7.35 & $3 \cdot 26-10 \cdot 20$ & & & 8.20 & $5.41-12.82$ & & & 5.62 & $2 \cdot 67-9.27$ & & & 5.08 & $0.84-8.76$ & 0.002 & & & $7 \cdot 27$ & $3 \cdot 19-10.07$ \\
\hline ID & $<0.01$ & 99 & 14 & & & 1 & 3 & & & 3 & 11 & & & 10 & 19 & & & & $113^{x}$ & 14 & & \\
\hline ID & $<6.0$ & 266 & 38 & & & 10 & 28 & & & 16 & 57 & & & 30 & 55 & & & & $322^{\mathrm{b}}$ & 39 & & \\
\hline Children (n) & & 275 & & & & 13 & & & & 63 & & & & 131 & & & & & 482 & & & \\
\hline Uncorrected BIS & $\mathrm{mg} / \mathrm{kg}$ & & & 5.78 & $2.59-8.18$ & & & $7 \cdot 18$ & $4.33-9.60$ & & & 7.20 & $3.54-9.80$ & & & 6.56 & 2.63-8.94 & 0.031 & & & $6 \cdot 14$ & $2.75-8.57$ \\
\hline ID & $<0.01$ & 40 & 15 & & & 1 & 8 & & & 5 & 8 & & & 13 & 10 & & & & $59^{c}$ & 12 & & \\
\hline ID & $<3.0$ & 80 & 29 & & & 2 & 15 & & & 15 & 24 & & & 35 & 27 & & & & $132^{y}$ & 27 & & \\
\hline Corrected BIS & $\mathrm{mg} / \mathrm{kg}$ & & & 5.78 & $2.59-8.18$ & & & $6 \cdot 24$ & $3.39-8.66$ & & & 4.91 & $1 \cdot 26-7.52$ & & & 5.52 & $1.61-7.90$ & 0.491 & & & 5.62 & $2 \cdot 13-7.92$ \\
\hline ID & $<0.01$ & 40 & 15 & & & 1 & 8 & & & 9 & 14 & & & 17 & 13 & & & & $67^{d}$ & 14 & & \\
\hline ID & $<3.0$ & 80 & 29 & & & 2 & 15 & & & 20 & 32 & & & 42 & 32 & & & & $144^{z}$ & 30 & & \\
\hline
\end{tabular}

ID, Fe deficiency.

w, x,a,b Values with unlike superscript letters were significantly different in the number of women with ID defined by low BIS before and after correction (w, $\mathrm{x}$ for $<0.01 \mathrm{mg} / \mathrm{kg}$ and a,b for $<6.0 \mathrm{mg} / \mathrm{kg})(P<0.005 ;$ paired $t$ test on coded data).

作,c,d Values with unlike superscript letters were significantly different in the number of children with ID defined by low BIS before and after correction $(y, z$ for $<0.01 \mathrm{mg} / \mathrm{kg}$ and $\mathrm{c}, \mathrm{d}$ for $<3.0 \mathrm{mg} / \mathrm{kg})(P<0.005$; paired $t$ test on coded data).

*BIS data are presented as medians and quartiles. ID (BIS $<0.01$ and $<3$ or $6 \mathrm{mg} / \mathrm{kg}$ ) is shown as numbers and percentages.

†The four inflammation groups were as follows: reference, no raised acute-phase protein concentrations; incubation, only C-reactive protein (CRP) concentrations raised (>5 mg/l); early convalescence, both CRP and $\alpha-1$-acid glycoprotein (AGP) (>1 g/l) concentrations raised; late convalescence, only AGP concentrations raised.

¥Corrected BIS calculated using inflammation-corrected ferritin (Table 2) and uncorrected sTRR (Table 3) concentrations.

$\S$ Differences between the inflammation groups were determined by the Kruskal-Wallis test for non-parametric data. 
Table 5. Influence of inflammation on $\mathrm{Hb}$ concentrations in non-pregnant women and children* $† \ddagger$ (Mean values and standard deviations; number of subjects and percentages)

\begin{tabular}{|c|c|c|c|c|c|c|c|c|c|c|c|c|c|c|c|c|c|c|c|c|c|}
\hline \multirow{2}{*}{ Variables } & \multicolumn{4}{|c|}{ Reference } & \multicolumn{4}{|c|}{ Incubation } & \multicolumn{4}{|c|}{ Early convalescence } & \multicolumn{4}{|c|}{ Late convalescence } & \multirow[b]{2}{*}{$P \S$} & \multicolumn{4}{|c|}{ Total } \\
\hline & Mean & SD & $n$ & $\%$ & Mean & SD & $n$ & $\%$ & Mean & SD & $n$ & $\%$ & Mean & SD & $n$ & $\%$ & & Mean & SD & $n$ & $\%$ \\
\hline Number of women $(n)$ & 694 & & & & 36 & & & & 28 & & & & & 54 & & & & 812 & & & \\
\hline $\mathrm{Hb}(\mathrm{g} / \mathrm{l})$ & $122 \cdot 2^{\mathrm{a}}$ & $16 \cdot 1$ & & & $129 \cdot 3^{b}$ & $12 \cdot 3$ & & & $120 \cdot 5^{\mathrm{a}, \mathrm{c}}$ & $19 \cdot 0$ & & & $116 \cdot 2^{b, c}$ & $20 \cdot 0$ & & & 0.003 & $122 \cdot 0$ & $16 \cdot 4$ & & \\
\hline Anaemia & & & 256 & $36 \cdot 9$ & & & 8 & $22 \cdot 2$ & & & 13 & $46 \cdot 4$ & & & 26 & $48 \cdot 1$ & & & & $303^{x}$ & $37 \cdot 3$ \\
\hline $\mathrm{CF}$ & & & & & 0.945 & & & & 1.014 & & & & 1.052 & & & & & & & & \\
\hline Corrected $\mathrm{Hb}(\mathrm{g} / \mathrm{l})$ & $122 \cdot 2$ & $16 \cdot 1$ & & & $122 \cdot 2$ & $11 \cdot 6$ & & & $122 \cdot 2$ & $19 \cdot 3$ & & & $122 \cdot 3$ & $21 \cdot 1$ & & & 1.00 & $122 \cdot 2$ & $16 \cdot 4$ & & \\
\hline Corrected anaemia & & & 256 & $36 \cdot 9$ & & & 14 & 39.0 & & & 13 & $46 \cdot 4$ & & & 22 & $40 \cdot 7$ & & & & $305^{x}$ & 37.6 \\
\hline Number of children $(n)$ & 274 & & & & 12 & & & & 63 & & & & 130 & & & & & 479 & & & \\
\hline $\mathrm{Hb}(\mathrm{g} / \mathrm{l})$ & $111.9^{a}$ & $12 \cdot 3$ & & & $102 \cdot 4^{b}$ & 14.5 & & & $107 \cdot 0^{\mathrm{b}}$ & $14 \cdot 3$ & & & $111 \cdot 2^{\mathrm{a}}$ & $13 \cdot 0$ & & & 0.006 & $110 \cdot 8$ & $13 \cdot 0$ & & \\
\hline $\begin{array}{l}\text { Anaemia } \\
\mathrm{CF}\end{array}$ & & & 105 & $28 \cdot 3$ & 100 & & 8 & $66 \cdot 7$ & 105 & & 32 & $50 \cdot 8$ & 101 & & 49 & $37 \cdot 7$ & & & & $194^{y}$ & 40.5 \\
\hline Corrected $\mathrm{Hb}(\mathrm{g} / \mathrm{l})$ & 111.8 & $12 \cdot 3$ & & & $\begin{array}{l}1.09 \\
111.6\end{array}$ & $15 \cdot 8$ & & & $\begin{array}{l}1.05 \\
112.3\end{array}$ & $15 \cdot 0$ & & & $\begin{array}{l}1.01 \\
112.4\end{array}$ & $13 \cdot 2$ & & & 0.98 & $112 \cdot 0$ & $13 \cdot 0$ & & \\
\hline Corrected anaemia & & & 105 & $28 \cdot 3$ & & & 4 & 33.3 & & & 23 & $36 \cdot 5$ & & & 48 & $36 \cdot 9$ & & & & $180^{z}$ & 37.6 \\
\hline
\end{tabular}

$\mathrm{CF}$, correction factor.

${ }^{\mathrm{a}, \mathrm{b}, \mathrm{c}}$ Mean values with unlike superscript letters were significantly different between the inflammation groups tested between the groups $(P<0.05 ;$ ANOVA followed by least significant difference $t$ test).

$\times$ Values with unlike superscript letters were significantly different in the proporions of women with anaemia before and after correction $(P<0.001$; paired $t$ test on coded data).

y,zalues with unlike superscript

in women and $<110 \mathrm{~g} / \mathrm{l}$ in children, is shown as numbers and percentage of total group numbers.

†The four inflammation groups were as follows: reference, no raised acute-phase protein concentrations; incubation, only C-reactive protein (CRP) concentrations raised (>5 mg/l); early convalescence, both CRP and $\alpha-1$-acid

glycoprotein (AGP) ( $\mathrm{g} / /$ ) concentrations raised; late convalescence, only AGP concentrations raised.

$\S$ Differences between the inflammation groups were determined by ANOVA. 
Table 6. Correlations between $\mathrm{Hb}$, acute-phase proteins and indices of iron status in women and children*

\begin{tabular}{|c|c|c|c|c|c|c|c|}
\hline & & & $\begin{array}{l}\text { Body Fe store } \\
\text { corrected }\end{array}$ & $\log _{10} \operatorname{TfR}$ & $\begin{array}{l}\log _{10} \text { ferritin } \\
\text { corrected }\end{array}$ & $\log _{10}$ CRP & $\log _{10} A G P$ \\
\hline \multirow[t]{2}{*}{ Women ( $n$ 812) } & $\begin{array}{l}\log _{10} \text { inflammation- } \\
\text { corrected } \mathrm{Hb}\end{array}$ & Pearson's $r$ & 0.462 & -0.444 & 0.394 & 0.087 & 0.032 \\
\hline & & Significance two-tailed & 0.000 & 0.000 & 0.000 & 0.007 & $0 \cdot 181$ \\
\hline \multirow[t]{2}{*}{ Children ( $n$ 479) } & $\begin{array}{l}\text { Log }_{10} \text { inflammation- } \\
\text { corrected } \mathrm{Hb}\end{array}$ & Pearson's $r$ & 0.337 & -0.411 & 0.260 & -0.081 & 0.013 \\
\hline & & Significance two-tailed & 0.000 & 0.000 & 0.000 & 0.038 & 0.386 \\
\hline
\end{tabular}

TfR, transferrin receptors; CRP, C-reactive protein; AGP, $\alpha$-1-acid glycoprotein.

${ }^{*}$ Cross-correlations of Fe status biomarkers against $\mathrm{Hb}$ concentrations. 'Corrected' refers to data corrected for inflammation and log ${ }_{10}$ to transformation using logarithms to the base 10 .

boys and girls, respectively). As there was much more anaemia in both women and children than was detected as Fe deficiency by any of the three Fe indices, we examined Pearson's correlations and regression analysis between $\mathrm{Hb}$ and these three Fe indices and the APP.

Table 6 shows the correlation results using the logarithms for inflammation-adjusted $\mathrm{Hb}$, ferritin, CRP and AGP concentrations, and the logarithms of STfR concentrations (uncorrected) and BIS (calculated using inflammation-adjusted ferritin concentrations). Pearson's correlation coefficient $(r)$ values for ferritin, sTfR and BIS indicated that concentrations were strongly correlated with corrected $\mathrm{Hb}$ concentrations in both subject groups; similar results were found using uncorrected $\mathrm{Hb}$ concentrations. The APP CRP was weakly correlated with $\mathrm{Hb}$ in both women and children. We used multiple linear regression to explain the variance in log-transformed, inflammation-corrected $\mathrm{Hb}$ concentrations with models comprising either (1) log-corrected ferritin concentrations, log-uncorrected sTfR concentrations and the logarithms of CRP and AGP concentrations or (2) ferritin-corrected BIS and log-transformed CRP and AGP concentrations. With model 1, we found that STfR concentrations contributed most to the variance in $\mathrm{Hb}$ concentrations in both women (19.7\%, $P=0.000)$ and children $(16.8 \%, P=0.000)$. Ferritin concentrations in women and children explained a further 5.1 or $1.4 \%$ (respectively), and AGP concentrations added a further $1.1 \%$ in the case of women (stepwise multiple linear regression). Therefore, the total variance in $\mathrm{Hb}$ concentrations explained by the markers of $\mathrm{Fe}$ and inflammation was 25.9 and $18.3 \%$ in women and children, respectively. In model 2, the variance in $\mathrm{Hb}$ concentrations explained by BIS was 21.4 and $11.4 \%$ in women and children, respectively; APP concentrations contributed nothing further.

Lastly, we examined the BIS data in relation to anaemia (Table 7). A similar proportion of both women $(37.6 \%$, $305 / 812)$ and children $(37 \cdot 6 \%, 180 / 479)$ had anaemia, but the proportion with anaemia who also had zero BIS was $29 \%$ in women (89/305) and $29 \%$ in children (52/180). That is, the majority of women and children (both $71 \%$ ) with anaemia had positive BIS. There were only a small proportion of non-anaemic subjects who had zero BIS (women $4.7 \%$, 24/507; children $7 \%, 21 / 299$ ). We also examined the effects of using higher cut-offs for BIS $(<6$ and $<3 \mathrm{mg} / \mathrm{kg}$ for women and children, respectively) to include all subjects with low ferritin concentrations. Using the inflammation-corrected
BIS values, $39 \%$ of women and $30 \%$ of children fell into these low-BIS groups (Table 4 ) and the corresponding corrected $\mathrm{Hb}$ concentrations were 11.58 (SD 1.79) and 10.65 (SD 1.32) g/l for women and children, respectively. There was significantly more anaemia in the groups with low BIS than in the groups with $\mathrm{BIS}>6$ or $>3 \mathrm{mg} / \mathrm{kg}$ for women and children, respectively; for women, the prevalence of anaemia between these groups was $54 \%$ compared with $27 \%$, and for children, it was $58 \%$ compared with $29 \%$ ( $\chi^{2}$ test: both $\left.P<0.001\right)$. We also investigated differences in inflammation-corrected $\mathrm{Hb}$ concentrations between ferritin subgroups within these low-BIS groups; Hb concentrations were significantly higher (12.59 (SD 1.37) g/l) among women with ferritin concentrations $>15 \mu \mathrm{g} / 1$ than among women with ferritin concentrations $<15 \mu \mathrm{g} / \mathrm{l}$, where $\mathrm{Hb}$ concentration was $11 \cdot 16$ (SD 1.86) g/l $(P<0 \cdot 001)$. There was no difference in corrected $\mathrm{Hb}$ concentrations between the low- and high-ferritin subgroups ( $<$ or $>12 \mu \mathrm{g} / \mathrm{l})$ in children $(11.79(\mathrm{SD} 0.55) \mathrm{g} / 1 ; 12.02(\mathrm{SD} 0.73) \mathrm{g} / 1, P=0.06)$.

\section{Discussion}

We found that $14.5 \%$ of women and $42.9 \%$ of children had evidence of inflammation using elevated CRP and AGP concentrations as biomarkers of acute and chronic inflammation. As expected, the higher concentrations of ferritin in the inflammation groups than in the reference group indicated that ferritin concentrations were raised by inflammation and, less expectedly, so were sTfR concentrations. In addition, the ratio of plasma ferritin:sTfR concentrations used to calculate BIS was also higher in some of the inflammation groups

Table 7. Distribution of inflammation-corrected $\mathrm{Hb}$ and body iron store results in women and children* $† \ddagger$

(Number of subjects and percentages)

\begin{tabular}{|c|c|c|c|c|c|c|c|c|}
\hline & \multicolumn{4}{|c|}{ Zero body Fe stores } & \multicolumn{4}{|c|}{ Positive body Fe stores } \\
\hline & \multicolumn{2}{|c|}{ Anaemia } & \multicolumn{2}{|c|}{$\begin{array}{c}\text { No } \\
\text { anaemia }\end{array}$} & \multicolumn{2}{|c|}{ Anaemia } & \multicolumn{2}{|c|}{ No anaemia } \\
\hline & $n$ & $\%$ & $n$ & $\%$ & $n$ & $\%$ & $n$ & $\%$ \\
\hline Won & 89 & $10 \cdot 9$ & 24 & 3.0 & 216 & $26 \cdot 7$ & 483 & 59.5 \\
\hline Children & 52 & $10 \cdot 8$ & 21 & $4 \cdot 2$ & 128 & $29 \cdot 4$ & 278 & $58 \cdot 2$ \\
\hline
\end{tabular}

* Body Fe stores were calculated using inflammation-corrected ferritin and uncorrected soluble transferrin receptor concentrations. † Sample sizes were 812 for women and 479 for children.

$\ddagger$ Anaemia was defined as $<120 \mathrm{~g} / \mathrm{l}$ in women and $<110 \mathrm{~g} / \mathrm{l}$ in children. 
of both women and children, indicating sensitivity to inflammation as well. Most previous studies have found that sTfR was unaffected by the inflammatory response, on the basis of which it was proposed as a more useful tool for the assessment of $\mathrm{Fe}$ status in groups with a high prevalence of infection $^{(19,20)}$. However, in the present study, sTfR concentrations detected very little Fe deficiency and a significantly higher proportion of STfR values above $8.3 \mathrm{mg} / \mathrm{l}$ were found in the convalescent inflammation groups (Table 3 ). A recent study among Cambodian children aged 6-59 months has found a similar change in sTfR concentrations with inflammation: elevated log sTfR concentrations among children with raised AGP concentrations ${ }^{(21)}$ (equivalent to those in the convalescence groups in the present study). Convalescence follows illness, and during illness, an increase in hepcidin concentrations is likely to block erythropoiesis ${ }^{(22)}$. Hence, raised STfR concentrations during convalescence may well be a true indicator of higher erythropoietic requirements when the blockage diminishes. In the present study, we could not differentiate whether the higher STfR values in the convalescence groups were purely an inflammatory response or a genuine increase in erythropoiesis in the convalescent period. More work is needed to investigate this point, but in the present study, we decided not to correct sTfR concentrations to calculate BIS.

The median concentrations of ferritin in the reference groups of both women and children $(39 \cdot 0$ and $31 \cdot 1 \mu \mathrm{g} / \mathrm{l}$, respectively) were relatively high, with the effect that correction for inflammation had a relatively small effect on the numbers with Fe deficiency even though more than $40 \%$ of children had evidence of inflammation. However, after correcting the data for inflammation, low ferritin concentrations were helpful in detecting over five times more Fe deficiency in both women (26\%) and children (21\%) than did corrected elevated sTfR concentrations ( 5 and $3 \%$, respectively). This differs from the findings of the Cambodian study, where the prevalence of $\mathrm{Fe}$ deficiency among young children with normal $\mathrm{Hb}$ type ( $\mathrm{Hb} \mathrm{AA}$ ) was notably higher using an elevated STfR concentration as the biomarker than the prevalence based on low ferritin concentrations (corrected for inflammation). It is possible that the exclusion of variant $\mathrm{Hb}$ types in the Cambodian study contributed to this difference and is another point that should be further investigated. The use of the BIS ratio (BIS $<0.01 \mathrm{mg} / \mathrm{kg}$ ) in the Lao study was intermediately helpful in detecting Fe deficiency, $14 \%$ of both women and children.

In a population where over $40 \%$ of children have elevated APP concentrations, it is not practical to discard data with elevated APP concentrations from the assessment of population Fe deficiency. In addition, discarding subjects with inflammation would bias the sample remaining as both age and domicile influence the distribution of inflammation in both women and children (Table 1). Mburu et al. ${ }^{(5)}$ showed that ferritin concentrations can be adjusted to remove the effect of inflammation using CF based on CRP and AGP concentrations and that calculated $\mathrm{CF}$ were the same for children and women of reproductive age ${ }^{(14)}$. Using CF strengthens the assessment of the prevalence of Fe deficiency in a population since all data may be included. We used the CF generated by the meta-analysis of ferritin studies reported in $2010^{(14)}$. The Lao data sets were part of the meta-analysis and the CF may not have been fully appropriate as they were influenced by the other studies. However, the results of the meta-analysis have recently been corroborated by a completely independent study on Kenyan pre-school children ${ }^{(23)}$ where the use of the meta-analysis CF produced an increase in ID (from 26.9 to $39 \cdot 1 \%$ ) that was very similar to that obtained with the internally generated CF (40.7\%). In addition, we generated CF specifically from the Lao data and the results were not significantly different from those obtained using the meta-analysis CF (Table 2).

From data given in Table 1, we expect that since more children of younger age and from the south region showed evidence of inflammation, the application of CF will have removed any potential bias caused by age and location on ferritin concentrations and provided a more reliable estimate of Fe deficiency among all groups.

When BIS were calculated using either inflammationcorrected ferritin concentrations or uncorrected data, the number of subjects with zero Fe stores was not very different. Inflammation-corrected sTfR concentrations were not included in calculating the corrected BIS shown in Table 4; however, when they were included in the calculation, there was no effect on the number of children with zero BIS values and reduced the number of women with zero BIS to 111 (14\%) (data not shown). The relatively low prevalence of zero BIS values contrasts with the prevalence estimates for Fe deficiency based on corrected ferritin data $(26 \%$ women; $21 \%$ children) and with the total number of subjects with anaemia $(37.6 \%)$ in both women and children. Thus, both plasma sTfR concentrations and BIS were less useful than ferritin concentrations in detecting Fe deficiency in the present study.

We also examined whether higher cut-offs for BIS were better related to the anaemia data. We selected $<6$ and $<3 \mathrm{mg} / \mathrm{kg}$ in women and children, respectively, as these cut-offs included all subjects with low ferritin concentrations (i.e. $<15$ and $<12 \mu \mathrm{g} / \mathrm{l}$ ). In both women and children, there was significantly more anaemia in those with low BIS than in those with high BIS. Whether these higher cut-offs for BIS will prove to be of a greater value for predicting anaemia than a BIS value of zero will need to be tested in other studies.

There was a poor agreement between ferritin concentrations and anaemia as, in spite of considerable anaemia in both women and children (37.6\%), Fe-deficiency anaemia was only present in 16 and $13 \%$, respectively. To investigate which Fe biomarker was most closely related to anaemia, we used a regression analysis. We found that BIS explained $21.4 \%$ of the variance in corrected $\mathrm{Hb}$ concentrations in women but only $11.4 \%$ in children. BIS was calculated using ferritin and STfR concentrations, so the contribution to the variance in $\mathrm{Hb}$ concentrations made by each of the latter biomarkers was examined separately. We found that sTfR concentrations were the best predictor of $\mathrm{Hb}$ concentrations in both women (19.7\%) and children (16.9\%), while ferritin concentrations made a much lower contribution to the variance ( 5 and $1.4 \%$, respectively). That is, although low 
ferritin concentrations were present in 43\% (132/305) of women with anaemia and in 35\% (63/180) of children, ferritin concentrations were not as closely related to $\mathrm{Hb}$ as were sTfR concentrations.

The concentration of sTfR is a biomarker reflecting the demand for $\mathrm{Hb}$ synthesis. That is, there is an inverse relationship between the two variables, with low $\mathrm{Hb}$ concentrations stimulating sTfR synthesis. Fe deficiency restricts $\mathrm{Hb}$ synthesis; thus, an elevated sTfR concentration is a marker of $\mathrm{Fe}$ insufficiency; however, sTfR concentration is also increased in haemolytic anaemia, thalassaemia and other haemoglobinopathies $^{(21)}$. Part of the reason for the increase in STfR concentrations in haemoglobinopathies is because Fe stores are not fully available for erythropoiesis ${ }^{(24)}$; hence, a state of apparent Fe insufficiency may exist, which increases sTfR concentrations and also stimulates Fe absorption, even when Fe stores appear adequate. Haemoglobinopathies were not measured in the Lao survey, but are known to be common in South East Asia. A study in 412 pregnant women in Northeast Thailand has found that of seventy-one women with anaemia, forty-two $(59 \cdot 2 \%)$ had thalassaemia or $\mathrm{Hb} \mathrm{E}$ and only five $(7 \cdot 0 \%)$ had Fe deficiency ${ }^{(25)}$, and other studies conducted in the region have suggested that it is possible that from 20 to $70 \%$ of the survey population could have thalassaemia with or without one or other types of haemoglobinopathies, in particular, $\mathrm{Hb} \mathrm{E}$ trait $^{(21,26-29)}$. The type of interference that haemoglobinopathies can make to circulating Fe concentrations, in parallel to their effect of increasing anaemia, may be the reason for STfR concentrations, rather than ferritin concentrations (a measure of Fe stores), being more strongly associated with $\mathrm{Hb}$.

Another work has shown that after adjusting ferritin concentrations for inflammation, there was no significant difference in the arithmetic mean for ferritin concentrations between different $\mathrm{Hb}$ variants, indicating that ferritin concentrations still provide a measure of Fe stores in the presence of genetic $\mathrm{Hb}$ disorders ${ }^{(21,26)}$, which supports our conclusions on the use of adjusted ferritin results to assess Fe deficiency in the present study.

In conclusion, public health interventions to improve $\mathrm{Fe}$ status, while still necessary, may not result in the expected reductions in anaemia among populations such as that in The Lao PDR, since less than half the anaemia in the present study was due to Fe deficiency and Fe biomarkers only explained between 20 and $25 \%$ of the variance in $\mathrm{Hb}$ concentrations. Other evidence from the region has suggested that haemoglobinopathies may be a major contributor to anaemia, but were not measured in the present study. Likewise, deficiencies of haemopoietic vitamins are common in the region and may have contributed to anaemia ${ }^{(21,30)}$. The results indicate that anaemia should not be used as a proxy indicator for Fe deficiency among such populations with a high proportion of genetic $\mathrm{Hb}$ disorders. Inflammation-corrected low ferritin concentrations appeared to be a better indicator of Fe deficiency than either sTfR concentrations or BIS in this population of both women and children; however, sTfR concentrations were more strongly related to $\mathrm{Hb}$ than ferritin concentrations; thus, both ferritin and sTfR have a role in the assessment of the impact of public health interventions on the prevalence of Fe deficiency and anaemia.

\section{Acknowledgements}

The data used for the present analyses were obtained as part of a 2006 National Nutrition Survey in The Lao PDR. This survey was made possible due to financial and technical support from the US CDC, UNICEF Vientiane and the UNICEF Regional Office for East Asia and the Pacific. The preparation of this paper received no specific grant from any funding agency in the public, commercial or not-for-profit sectors. We are grateful to Ms B. Haynes (CDC), who trained the survey staff in blood collection techniques, provided oversight of related field supplies and logistics and reviewed the qualitycontrol data, and to Dr J. Erhardt (DBS Tech Laboratory, Germany), who measured the Fe biomarkers and APP. Contributions by the authors are as follows: J. K. and D. I. T. analysed the data and prepared the manuscript; B. P., K. P., I. K., K. K. and J. K. were responsible for planning and preparing the nutrition survey; K. H., K. K. and J. K. were responsible for data management, cleaning and initial analysis of the $\mathrm{Hb}$ data. All authors read and approved the manuscript. All authors report no conflicts of interest.

The authors dedicate this paper to the memory of Keonakhone Houamboun and would like to acknowledge his significant contribution to improving public health in the Lao PDR.

\section{References}

1. Gibson RS, Abebe Y, Stabler S, et al. (2008) Zinc, gravida, infection, and iron, but not vitamin B-12 or folate status, predict hemoglobin during pregnancy in Southern Ethiopia. J Nutr 138, 581-586.

2. UNICEF, UNU \& WHO (2001) Iron Deficiency Anaemia. Assessment, Prevention and Control. A Guide for Programme Managers no. WHO/NHD/01.3. Geneva: World Health Organization.

3. Thurnham DI, Mburu ASW, Mwaniki DL, et al. (2008) Using plasma acute-phase protein concentrations to interpret nutritional biomarkers in apparently healthy HIV-1-seropositive Kenyan adults. BrJ Nutr 100, 174-182.

4. Darboe MK, Thurnham DI, Morgan G, et al. (2007) Effectiveness of the new IVACG early high-dose vitamin A supplementation scheme compared to the standard WHO protocol: a randomised controlled trial in Gambian mothers and infants. Lancet 369, 2088-2096.

5. Mburu ASW, Thurnham DI, Mwaniki DL, et al. (2008) The influence and benefits of controlling for inflammation on plasma ferritin and hemoglobin responses following a multi-micronutrient supplement in apparently-healthy, HIV + Kenyan adults. J Nutr 138, 613-619.

6. Cook JD, Skikne BS \& Baynes RD (1993) Serum transferrin receptor. Ann Rev Med 44, 63-74.

7. Beesley R, Filteau SM, Tomkins A, et al. (2000) Impact of acute malaria on plasma concentrations of transferrin receptors. Trans R Soc Trop Med Hyg 94, 295-298.

8. Cook JD, Flowers CH \& Skikne D (2003) The quantitative assessment of body iron. Blood 101, 3359-3363.

9. Ganz T (2007) Molecular control of iron transport. J Am Soc Nephrol 18, 394-400. 
10. Thurnham DI, McCabe GP, Northrop-Clewes CA, et al. (2003) Effect of subclinical infection on plasma retinol concentrations and assessment of prevalence of vitamin A deficiency: meta-analysis. Lancet 362, 2052-2058.

11. Beard JL, Murray-Kolb LE, Rosales FJ, et al. (2006) Interpretation of serum ferritin concentrations as indicators of total-body iron stores in survey populations: the role of biomarkers for the acute phase response. Am J Clin Nutr 84, $1498-1505$.

12. Lao PDR (2006) Monitoring the situation of children and women. Multiple Indicator Cluster Survey. http://www. childinfo.org/files/MICS3_Lao_FinalReport_2006_Eng.pdf

13. Erhardt JG, Estes JE, Pfeiffer CM, et al. (2004) Combined measurement of ferritin, soluble transferrin receptor, retinol binding protein, and C-reactive protein by an inexpensive, sensitive, and simple sandwich enzyme-linked immunosorbent assay technique. J Nutr 134, 3127-3132.

14. Thurnham DI, McCabe LD, Haldar S, et al. (2010) Adjusting plasma ferritin concentrations to remove the effects of subclinical inflammation in the assessment of iron deficiency: a meta-analysis. Am J Clin Nutr 92, 546-555.

15. World Health Organization \& CDC (2004) Assessing the Iron Status of Populations. Geneva: WHO Press.

16. Centres for Disease Control and Prevention (1998) Recommendations to prevent and control iron deficiency in the United States. Morb Mortal Wkly Rep 47, 1-29.

17. Pritchett L \& Filmer D (2001) Estimating wealth effects without expenditure data - or tears: an application to educational enrolments in states of India. Demography $\mathbf{3 8}$, 115-132.

18. Rutstein SO \& Johnson K (2004) The DHS wealth index. In Demographic and Health Survey Comparative Reports, Volume 6. Calverton, MD: ORC Macro.

19. Punnonen K, Irjala K \& Rajamaki A (1997) Serum transferrin receptor and its ratio to serum ferritin in the diagnosis of iron deficiency. Blood 89, 1052-1057.

20. Olivares M, Tomás W, Cook JD, et al. (2000) Usefulness of serum transferrin receptor and serum ferritin in diagnosis of iron deficiency in infancy. Am J Clin Nutr 72, 1191-1195.
21. George J, Yiannakis M, Main B, et al. (2012) Genetic hemoglobin disorders, infection, and deficiencies of iron and vitamin A determine anemia in young Cambodian children. J Nutr 142, 781-787.

22. Collins JF, Wessling-Resnick M \& Knutson MD (2008) Hepcidin regulation of iron transport. J Nutr 138, 2284-2288.

23. Grant FK, Suchdev PS, Flores-Ayala R, et al. (2012) Correcting for inflammation changes estimates of iron deficiency among rural Kenyan preschool children. J Nutr 142, $105-111$

24. Zimmermann MB, Fucharoen S, Winichagoon P, et al. (2008) Iron metabolism in heterozygotes for hemoglobin $\mathrm{E}$ (HbE), alpha-thalassemia 1, or beta-thalassemia and in compound heterozygotes for HbE/beta-thalassemia. Am J Clin Nutr 88, 1026-1031.

25. Thurlow RA, Winichagoon P, Green T, et al. (2005) Only a small proportion of anemia in northeast Thai schoolchildren is associated with iron deficiency. Am J Clin Nutr 82, $380-387$.

26. Anderson VP, Jack S, Monchy D, et al. (2008) Co-existing micronutrient deficiencies among stunted Cambodian infants and toddlers. Asia Pac J Clin Nutr 17, 72-79.

27. Sanchaisuriya K, Fucharoen S, Ratanasiri T, et al. (2006) Thalassemia and hemoglobinopathies rather than iron deficiency are major causes of pregnancy-related anemia in northeast Thailand. Blood Cells Mol Dis 37, 8-11.

28. Savongsy O, Fucharoen S, Fucharoen G, et al. (2008) Thalassemia and hemoglobinopathies in pregnant Lao women: carrier screening, prevalence and molecular basis. Ann Hematol 87, 647-654.

29. Fucharoen G, Sanchaisuriya K, Sae-Ung N, et al. (2004) A simplified screening strategy for thalassaemia and haemoglobin $\mathrm{E}$ in rural communities in south-east Asia. Bull WHO 82, 364-372.

30. Fishman SM, Christian P \& West KP Jr (2000) Role of vitamins in the prevention and control of anaemia. Public Health Nutr 3, 125-150. 